\title{
Educational suitability of endotracheal intubation using a video-laryngoscope
}

\author{
Heon Jin Choo', Oh Young Kwon ${ }^{2}$ and Young Gwan Ko ${ }^{1}$ \\ Departments of ${ }^{1}$ Emergency Medicine and ${ }^{2}$ Medical Education and Medical Humanities, Kyung Hee University \\ School of Medicine, Seoul, Korea
}

\section{비디오 후두경을 이용한 기관내 삽관의 교육 적합성}

경희대학교 의학전문대학원 ${ }^{1}$ 응급의학교실, ${ }^{2}$ 의학교육 및 의인문학교실

추헌진 ${ }^{1}$, 권오영 $^{2}$, 고영관 $^{1}$

Purpose: The purpose of this study is to determine the educational suitability of the video-laryngoscope in teaching endotracheal intubation to students.

Methods: Medical students participated in a course on the use of a Macintosh direct laryngoscope and McGrath MAC videolaryngoscope for intubation. The course comprised a 1-hour lecture and 30 minutes of practice on a manikin. After the course, in each of the three simulated patient scenarios - normal airway, cervical spine fixation, and tongue edema-time to intubate, success rate, and chance of complications were measured. A questionnaire was administered before and after the course to determine the suitability of intubation by video-laryngoscope for a medical education course. Also, changes in the perception and stance on the video-laryngoscope were evaluated.

Results: Time to intubate decreased as attempts were repeated. The first-attempt success rate in the cervical spine fixation scenario was higher using the video-laryngoscope $(p=0.028)$. Rates if tooth injury were lower in the cervical spine fixation $(p=0.005)$ and tongue edema scenarios ( $p=0.021)$ using the video-laryngoscope. Based on the questionnaires, students responded positively with regard to their knowledge of the video-laryngoscope, its practical value, and its suitability for medical education ( $p<0.001)$. Also, the preference for the video-laryngoscope was greater $(p=0.044)$. Students felt that repeated attempts and feedback on intubation were helpful.

Conclusion: The students' evaluations and surveys showed positive results to intubation by video-laryngoscope. Thus, based on its suitability for medical education it is reasonable to consider learning intubation using the video-laryngoscope.

Key Words: Video laryngoscope, Intratracheal intubation, Medical education, Manikins, Students

Received: July 17, 2015 • Revised: September 6, 2015 • Accepted: September 7, 2015 Corresponding Author: Oh Young Kwon (http://orcid.org/0000-0003-0817-2256) Department of Medical Education and Medical Humanities, Kyung Hee University School of Medicine, 26 Kyungheedae-ro, Dongdaemun-gu, Seoul 02447, Korea

Tel: +82.2.961.9102 Fax:+82.2.969.6958 email: koy0004@hotmail.com
Korean J Med Educ 2015 Dec; 27(4): 267-274. http://dx.doi.org/10.3946/kjme.2015.27.4.267 eISSN: $2005-7288$

(C) The Korean Society of Medical Education. All rights reserved. This is an open-access article distributed under the terms of the Creative Commons Attribution Non-Commercial License (http:// creativecommons.org/licenses/by-nc/3.0/), which permits unrestricted non-commercial use, distribution, and reproduction in any medium, provided the original work is properly cited. 
를 분석하고자 하였다.

\section{서론}

기관내 삽관은 기도유지, 저산소증 교정 등의 목적으로 응급 상황에서 짧은 시간 안에 신속하게 시행해야 할 필수적인 술기 로 현재 대한민국 의사국가시험 실기시험 중 객관구조화진료시 험(objective structured clinical examination, OSCE) 항목 의 하나로 시행되고 있다. 기관내 삽관을 위해 일반적으로 매킨 토시 직접 후두경을 사용하고 있으나 $90 \%$ 이상의 성공률을 보이기 위해서는 약 47 56회에 이르는 많은 경험이 필요하며 다수의 경험이 있다 하더라도 어려운 기도에서 기관내 삽관을 성공하는 것은 매우 어려울 수 있다[1]. 삽관이 필요한 전체 환자 중 어려운 삽관의 비율은 문헌에 따라 편차는 크나 약 6\% 30\%에 이른다고 한다[2,3]. 이를 극복하기 위해 비디오 후두경, 성문외 기구, 윤상갑상막 절개술 등을 시행하며 상황에 따라서 직접 후두경보다 우선적으로 쓰기도 한다[4]. 이 중 비 디오 후두경은 전 연령대에 시행할 수 있고 비침습적 방법으로 확실한 기도를 확보할 수 있는 장점이 있다. 또한 기관내 삽관 시 직접 후두경에 비해 경추에 가해지는 움직임을 줄일 수 있고 어려운 삽관 및 합병증의 비율을 감소시키며, 첫 시도에 성공률 이 더 높다고 조사되었다[5,6].

Sakles et al. [7]에 따르면 약 43\%의 응급실에서 비디오 후 두경을 보유하고 있다고 하였고 국내 많은 대학병원에서도 이 기구를 보유하고 있으며 최근 그 사용은 꾸준히 늘고 있다. 현재 우리나라의 의학교육에서 기관내 삽관을 응급의학과, 마취통증의학과, 또는 내과 등에서 교육하고 있으나 비디오 후두경을 통한 기관내 삽관 교육은 잘 이루어지지 않거나 간 단한 소개 정도로 언급되는 경우가 많다. 하지만 최근 해외뿐 만 아니라 국내에서도 학생이나 수련의, 응급 구조사를 대상 으로 비디오 후두경을 통한 기관내 삽관에 대한 논문이 발표 되고 있다[8,9,10].

본 연구의 목적은 매킨토시 직접 후두경과 비디오 후두경 을 통한 기관내 삽관의 교육 적합성을 학생들을 대상으로 검 증하는 데 있다. 이를 검증하기 위해 실습 평가와 설문을 이용 하였으며 실습 평가는 정상기도 및 어려운 기도 시나리오에 서 각 후두경을 통한 삽관의 술기 습득의 용이성을 비교 분석 하였고 실습 전후 설문을 통해 그에 대한 학생들의 태도 변화

\section{대상 및 방법}

\section{1. 장비}

이번 연구에 사용된 비디오 후두경은 $\mathrm{McGrath} \mathrm{MAC}$ video laryngoscope (Aircraft Medical, Edinburgh, UK)으 로 모니터와 몸체, 그리도 날을 끼울 수 있는 카메라 막대 일 체형으로 되어 있다(Fig. 1). 카메라 막대에 2, 3, 4번 사이즈 의 플라스틱 일회용 후두경 날을 결합하여 사용할 수 있다. 모 니터는 2.5 인치로 몸체와 연결부위는 각도 조절이 가능해 다 양한 시야를 확보할 수 있으며, 리튬 일회용 배터리를 전원으 로 사용한다.

교육 및 연습 시에 사용한 마네킹은 Laerdal Airway Management Trainer (Laerdal, Stavanger, Norway)를 사용 하였고 평가 시에는 Emergency Care Simulator (ECS-100) Task Trainer (Medical Education Technologies Inc., Orlando, USA)를 사용하였다. 삽관 시 $7.5 \mathrm{~mm}$ 삽관튜브를 사용하였고 매킨토시 후두경 날과 McGrath 후두경 날은 모두

Fig. 1. Photograph of McGrath MAC Video-Laryngoscope (Aircraft Medical)

(A)

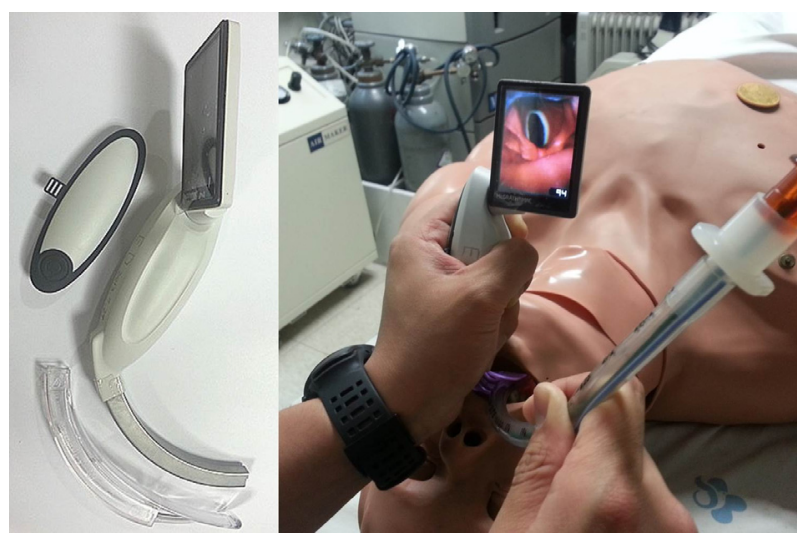

It contains a 2.5-inch screen topping the handle, camera stick with an integrated light source, disposable transparent blades, and 3.6 $\mathrm{V}$ battery $(\mathrm{A})$. Photograph showing endotracheal intubation using McGrath MAC video-laryngoscope and a vocal cord of manikin in display screen $(B)$. 
동일한 3 번 사이즈를 사용하였다.

\section{2. 연구 대상 및 방법}

의학전문대학원 4학년 학생 46명을 대상으로 이 연구를 진

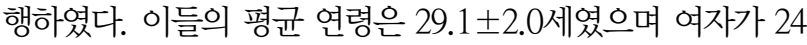
명(52\%)이었다. 기관내 삽관 교육과정은 1일차 이론 교육, 2 일차 실습교육을 각각 한 시간씩 실시하였고 2일차 실습교육 직후 실습평가를 진행하였다. 교육과 평가는 1 인의 응급의학 과 전문의와 1 인의 전공의에 의해 교육당 $5 \sim 6$ 명을 한 조로 총 9 개 조로 편성 후 조당 한 주씩 총 9주에 걸쳐 본교 임상수 기센터에서 실습을 진행하였다. 이론 교육은 슬라이드 강의 자료를 이용하였고, 기관내 삽관의 적응증 및 목적, 합병증, 술기과정을 포함하였으며 이론 교육이 실시되기 전에 사전 설문조사를 시행하였다. 실습 교육은 전공의 1 인이 매킨토시 후두경과 비디오 후두경을 이용하여 시연 및 질의응답 시간 을 가진 후 학생들은 30 분 동안 각자 연습을 하였다. 평가는 교육을 담당하였던 응급의학과 전문의 1 인과 전공의 1 인이 시행하였으며, 두 후두경 간의 기관내 삽관 술기를 비교 평가 하기 위해 치아손상 및 식도삽관 여부, 기관내 삽관의 최종 성 공 여부 및 1 차 시도 시 성공 여부, 기관내 삽관 동안 걸린 시 간(초)을 측정하였다. 평가를 포함한 모든 교육과정이 종료된 후 사후 설문조사를 시행하였다.

실제와 유사한 3 가지 상황을 설정하여 다음과 같은 시뮬레이 션 시나리오를 제작하였다. 첫째, 정상 기도(normal airway) 시나리오, 둘째, 경부고정(cervical spine fixation) 시나리오. 마지막으로 혀부종(tongue edema) 시나리오이다. 정상 기도 시나리오에서는 기관내 삽관 시 아무런 제한을 두지 않았고, 경부고정 시나리오에서는 필라델피아 경추 보호대로 경추를 고정하여 두부 및 경추의 움직임을 제한하였고, 혀부종 시나 리오는 앞서 언급한 마네킹에 조작을 가하여 혀부종을 설정 하여 삽관 시 시야확보를 제한하였다. 모든 학생은 3 가지 시 나리오에서 매킨토시 후두경과 비디오 후두경을 이용하여 총 6회의 삽관을 시행하였으며 시나리오 순서와 두 후두경의 사 용 순서는 모두 난수표에 의해 무작위로 정하였다. 각각의 삽 관 사이에는 5 분간의 휴식이 주어졌고, 휴식시간에 현장 피드 백이 이루어졌다. 각 기관내 삽관의 성공은 인공환기기를 연 결했을 때 폐가 부풀어 오르는 것으로 판정하였으며, 식도에
삽관이 되었거나 삽관 시간이 45 초를 초과했을 때 실패로 간 주하였다. 후두경을 구강에 삽입하면 삽관 시도로 간주하였 으며, 시도 횟수는 최대 3회로 제한하였다[8].

평가 전과 후 각각 사전에 고안된 설문을 이용하여 비디오 후두경을 이용한 기관내 삽관 술기의 교육과정 적절성에 대 한 인식 및 태도의 변화를 평가하였다. 실습 전 설문 항목은 7가지였으며 비디오 후두경에 대한 지식, 실제 환자에 적용 가능성 및 대처능력, 교육적합성, 임상 상황 별 선호하는 후두 경을 확인하였고, 실습 후 설문 항목은 사전설문과 동일한 7 가지 항목에 비디오 후두경의 교육기회, 졸업 후 기관내 삽관 상황의 직면 가능성, 추후 재교육 의지, 현장 피드백과 반복 시도에 관한 5 항목을 추가하여 총 12 항목으로 구성하였다. 대 부분 문항에 대한 평가는 5단계 척도를 사용하여 1단계는 '매 우 아니다', 5단계는 '매우 그렇다'로 정하였다.

\section{3. 분석 방법}

모든 통계학적 분석은 SPSS version 21.0 (IBM Corp., Chicago, USA)를 사용하였다. 기관 삽관 동안 걸린 시간, 사 전-사후 설문 공통문항의 분석에는 대응표본 $\mathrm{t}$ 검정을 이용 하였고, 기관내 삽관의 최종 성공 여부 및 1 차 시도 성공 여 부, 삽관 및 치아손상 여부를 분석하기 위해 chi-square 검정 을 사용하였다. 유의수준의 $\mathrm{p}$ 값은 0.05 미만으로 정하였다.

\section{결과}

\section{1. 각 후두경을 통한 기관내 삽관의 결과 비교}

비디오 후두경을 통한 기관내 삽관은 3 가지 시나리오에서 46명 모두 3차 시도 내에 성공하였고, 혀부종 시나리오에서 1 차 성공률이 가장 낮았다. 정상기도 시나리오에서 시기별 시 행시간은 1 차는 23.4 초, 2 차는 20.8 초, 경부고정 시나리오에 서 1차는 24.4초, 2차는 20.5초, 3차는 9초, 혀부종 시나리오 에서 1차는 29.7초, 2차는 19.4초로 조사되어 시도 횟수가 증 가할수록 술기에 소요되는 시간은 단축되었다(Table 1).

기관내 삽관을 완료하는 데 소요된 전체 시간 및 1 차 시도 에 소요된 시간, 전체 성공률, 식도삽관 여부는 모든 시나리오 
Table 1. Number of Successful Endotracheal Intubations and Mean Procedural Time

\begin{tabular}{|c|c|c|c|c|c|c|}
\hline \multirow{2}{*}{ Trial } & \multicolumn{3}{|c|}{ Macintosh } & \multicolumn{3}{|c|}{ McGrath } \\
\hline & First & Second & Third & First & Second & Third \\
\hline \multicolumn{7}{|l|}{ No. of successes } \\
\hline Normal airway & $43(93.5)$ & $3(6.5)$ & 0 & 42 (91.3) & $4(8.7)$ & 0 \\
\hline Cervical spine fixation & 41 (89.1) & $4(8.7)$ & $1(2.2)$ & 42 (91.3) & $3(6.5)$ & $1(2.2)$ \\
\hline Tongue edema & 33 (71.7) & $10(21.7)$ & $3(6.5)$ & $38(82.6)$ & $8(17.4)$ & 0 \\
\hline \multicolumn{7}{|c|}{ Mean procedural time (sec) } \\
\hline Normal airway & $23.3 \pm 13.8$ & $22.0 \pm 9.8$ & - & $23.4 \pm 10.9$ & $20.8 \pm 7.4$ & - \\
\hline Cervical spine fixation & $28.3 \pm 12.0$ & $20.4 \pm 15.4$ & 13.0 & $24.4 \pm 10.6$ & $20.5 \pm 16.3$ & 9.0 \\
\hline Tongue edema & $30.8 \pm 11.2$ & $22.9 \pm 14.0$ & $30.0 \pm 15.0$ & $29.7 \pm 12.1$ & $19.4 \pm 6.9$ & - \\
\hline
\end{tabular}

Data are presented as number $(\%)$ or mean \pm standard deviation.

Table 2. Comparison of Outcomes between Direct and Video-Laryngoscopes in Three Manikin Scenarios

\begin{tabular}{|c|c|c|c|}
\hline & Normal airway & Cervical spine fixation & Tongue edema \\
\hline \multicolumn{4}{|c|}{ Time for intubation } \\
\hline Macintosh & $23.3 \pm 13.8$ & $30.8 \pm 18.0$ & $39.5 \pm 27.7$ \\
\hline McGrath & $25.2 \pm 15.4$ & $26.3 \pm 16.0$ & $33.0 \pm 17.7$ \\
\hline $\mathrm{p}$-value & 0.472 & 0.184 & 0.129 \\
\hline \multicolumn{4}{|c|}{ Time for the attempt } \\
\hline Macintosh & $22.0 \pm 9.8$ & $28.3 \pm 12.0$ & $30.8 \pm 11.2$ \\
\hline McGrath & $23.4 \pm 10.9$ & $24.4 \pm 10.6$ & $29.7 \pm 12.1$ \\
\hline $\mathrm{p}$-value & 0.368 & 0.056 & 0.576 \\
\hline \multicolumn{4}{|c|}{ No. of overall successes } \\
\hline Macintosh & $46(100.0)$ & $45(97.8)$ & 45 (97.8) \\
\hline McGrath & $46(100.0)$ & $46(100.0)$ & $46(100.0)$ \\
\hline $\mathrm{p}$-value & & 0.315 & 0.315 \\
\hline \multicolumn{4}{|c|}{ No. of first-attempt successes } \\
\hline Macintosh & $43(93.5)$ & $34(73.9)$ & 32 (69.6) \\
\hline McGrath & 42 (91.3) & 42 (91.3) & 38 (82.6) \\
\hline $\mathrm{p}$-value & 0.694 & 0.028 & 0.143 \\
\hline \multicolumn{4}{|c|}{ No. of esophageal intubations } \\
\hline Macintosh & 0 & 7 (15.2) & $3(6.5)$ \\
\hline McGrath & 0 & $1(2.2)$ & 0 \\
\hline $\mathrm{p}$-value & - & 0.059 & 0.078 \\
\hline \multicolumn{4}{|c|}{ No. of tooth injuries } \\
\hline Macintosh & $4(8.7)$ & 19 (41.3) & 18 (39.1) \\
\hline McGrath & $4(8.7)$ & 7 (15.2) & $8(17.4)$ \\
\hline $\mathrm{p}$-value & 1.000 & 0.005 & 0.021 \\
\hline
\end{tabular}

Data are presented as mean \pm standard deviation or number $(\%)$.

에서 통계적으로 유의하지 않았다(Table 2). 1차 시도 성공률 은 경부고정 시나리오에서 비디오 후두경을 통한 삽관에서 더 높았다 $(\mathrm{p}=0.028)$. 경부고정 시나리오 $(\mathrm{p}=0.005)$ 와 혀부종 시나리오 $(\mathrm{p}=0.021)$ 모두에서 비디오 후두경을 이용하여 삽관 한 경우에서 매킨토시 후두경을 이용한 경우보다 치아손상이
유의하게 적었다.

\section{2. 비디오 후두경을 통한 기관내 삽관에 대한 태도 변화}

실습에 참여한 46명 학생 모두가 설문지 작성에 응하였다. 
Table 3. Comparative Questionnaire Analysis between Pre- and Postendotracheal Intubation

\begin{tabular}{|c|c|c|c|c|c|}
\hline \multirow{2}{*}{ Contents } & \multicolumn{2}{|c|}{ Pretest } & \multicolumn{2}{|c|}{ Posttest } & \multirow{2}{*}{ p-value } \\
\hline & Mean & SD & Mean & SD & \\
\hline Can understand and explain video-laryngoscope? & 2.87 & 1.00 & 4.48 & 0.59 & 0.000 \\
\hline Can understand the situation when video-laryngoscope is being used? & 3.02 & 0.98 & 4.41 & 0.58 & 0.000 \\
\hline Can perform video-laryngoscope intubation in real patients? & 1.98 & 1.22 & 4.30 & 0.59 & 0.000 \\
\hline Is video-laryngoscope appropriate for medical education? & 4.13 & 0.69 & 4.67 & 0.47 & 0.000 \\
\hline \multirow[t]{2}{*}{ Can deal with situation where intubation is required? } & 2.17 & 1.14 & 4.09 & 0.63 & 0.000 \\
\hline & $\mathrm{DL}$ & $\mathrm{VL}$ & $\mathrm{DL}$ & $\mathrm{VL}$ & \\
\hline Which laryngoscope will you choose for intubation? (\%) & $34(74.9)$ & $12(26.1)$ & $26(56.5)$ & $20(43.5)$ & 0.044 \\
\hline In difficult airways, which laryngoscope will you choose for intubation? $(\%)$ & $4(8.7)$ & $42(91.3)$ & $1(2.2)$ & $45(97.8)$ & 0.183 \\
\hline
\end{tabular}

Item: 1 (very poor)-5 (very good).

SD: Standard deviation, DL: Direct laryngoscope, VL: Video-laryngoscope.

Table 4. Questionnaire Analysis after Endotracheal Intubation

\begin{tabular}{lcc}
\hline \multicolumn{1}{c}{ Contents } & Mean & SD \\
\hline Do you expect that you will learn about the video-laryngoscope after graduation? & 2.87 & 1.11 \\
Do you expect to confront a moment when endotracheal intubation is needed after graduation? & 4.74 & 0.53 \\
Are you willing to reapply to an education course of the video-laryngoscope in the future? & 4.57 & 0.58 \\
Was feedback after endotracheal intubation helpful for the next attempt? & 4.85 & 0.36 \\
Did repeated attempts help in shortening the time to intubate? & 4.91 & 0.28 \\
\hline
\end{tabular}

Item: 1 (very poor)-5 (very good).

SD: Standard deviation.

실습교육 전후의 설문 비교 결과 '실제 환자에게 비디오 후두 경을 통한 기관내 삽관을 할 수 있는가?' 항목의 중앙값은 ‘매 우 아니다'에서 '그렇다'로 가장 큰 변화를 보였다 $(\mathrm{p}=0.000)$. 그 외에도 '비디오 후두경에 대해 알고 설명할 수 있는가? 항 목은 '보통이다'에서 '매우 그렇다' $\mathrm{p}=0.000)$ 로, '비디오 후두 경이 어떠한 임상상황에 쓰이는지 알고 있는가? 항목은 '보통 이다'에서 '그렇다' $(\mathrm{p}=0.000)$ 로, '비디오 후두경을 통한 기관내 삽관은 의학 교육에 적합한가?' 항목은 '그렇다에서 '매우 그 렇다' $(\mathrm{p}=0.000)$ 로, '기관내 삽관이 필요한 상황에 잘 대처할 수 있는가?' 항목은 ‘아니다'에서 ‘그렇다' $(\mathrm{p}=0.000)$ 로 역시 유 의하게 상승하였다. '기관내 삽관이 필요한 모든 환자에게 어 떤 후두경을 사용하여 삽관을 시도할 것인가? 항목에서 실습 전후 비디오 후두경을 선택한다는 학생의 수가 12 명(26.1\%) 에서 20명(43.5\%)으로 유의하게( $\mathrm{p}=0.044)$ 증가한 반면, '어려 운 기도 환자에게 어떤 후두경을 사용하여 삽관을 시도할 것 인가?' 항목에서는 실습 전후 비디오 후두경을 선택하는 학생 의 수가 42명(91.3\%)에서 45명(97.8\%)으로 유의한 변화를 보
이지 않았다(Table 3).

평가 후 설문에서 '졸업 후 비디오 후두경을 교육받을 기회 가 있을 것으로 예상합니까? 항목의 중앙값은 '아니다'와 '보 통이다였으나, 졸업 후 기관내 삽관이 필요한 상황을 직면할 가능성 및 재교육에 참여 여부에 대한 항목 모두 중앙값은 '매 우 그렇다'로 응답하였다. 또한 시뮬레이션 교육에서 중요하 게 여겨지는 반복 시도나 현장 피드백에 '매우 그렇다'로 긍정 적인 답변을 보였다(Table 4).

\section{고찰}

의사국가시험에서 현재 임상술기 항목 중 기관내 삽관은 응급 상황에서 환자의 생명과 직결되는 매우 중요한 술기 중 하나이다. 임상에서 통상적으로 시행하는 매킨토시 직접 후 두경을 통한 기관내 삽관은 외관상 기관내 삽관이 어려워 보 이거나, 외상이나 부종에 의한 기도폐쇄가 의심되는 경우와, 
큰 혀, 비만 환자, 경추의 움직임이 제한된 환자 등에서는 성 공하기 쉽지 않고, 성공에도 많은 시간이 소요된다[8,10]. 기 존 연구에서 직접 후두경외 선택할 수 있는 주요 술기 중 첫 번째로 성문외 기구는 이름 그대로 성문내 삽관을 하지 않아 확실한 기도의 확보가 어려워 양압 환기 시 밀착이 어렵고 위 팽창 및 위 내용물의 역류로부터 완전히 보호되지 않는 단점 이 있다[11]. 즉, 다른 술기에 비해 기관내 삽관의 본래 목적 인 적절한 환기와 확실한 기도의 확보에 다소 어려움이 따른 다. 두 번째로 윤상갑상막 절개술은 다른 술기에 비해 침습적 이고 10 세 미만의 소아에게는 절대적 금기이며 시행시간의 평균 또는 중간 값이 40 181.5초로 몇 배 이상 소요된다[12]. 또한 윤상갑상막 절개술의 시행률은 약 $1 \%$ 로 적절한 교육을 하기에는 그 사례가 너무 적다[11].

현재 비디오 후두경은 응급기도관리 및 수술 전 기관내 삽 관이 필요한 상황 등에서 시행되고 있으며 어려운 기도가 의 심되거나 실패한 기도에서 더욱 강조된다[4]. 병원 내뿐 아니 라 병원 전 단계에서 심정지 환자 또는 급· 만성 질환으로 인 한 호흡곤란 및 중증 외상환자에게 신속한 기도유지를 강조 하고 있고 이를 배경으로 응급 구조사들을 대상으로도 비디 오 후두경을 통한 기관내 삽관에 대한 연구가 진행되고 있다 [9,13]. 하지만 국내에서 비디오 후두경을 통한 기관내 삽관 의 교육 적합성을 실습평가와 설문과 같은 직간접적 두 가지 방법 모두로 검증한 논문은 아직 없었다.

학생 및 응급 구조사가 참여한 마네킹을 대상으로 한 기존 연구에서 두 연구 모두 6회 이상의 반복실습을 시행하였고 3 회 이상의 시도에서 지속적인 95\% 이상의 성공률과 10 25초 사이의 일정한 시행시간을 보였다[8,14]. $90 \%$ 의 성공률을 보 이기 위해서 약 50회의 경험이 필요한 매킨토시 직접 후두경 보다 적은 경험 및 실습으로 보다 빠르게 숙련도를 높일 수 있다[1]. 본 연구에는 비디오 후두경의 3 차 시도가 1 명으로 직접적으로 비교하기는 어려우나 모든 시나리오에서 1 차보다 는 2차 시도에서 모두 소요시간은 단축되었다.

마네킹을 대상으로 학생들이 참여한 기존의 비디오 후두경 을 통한 기관내 삽관까지 걸린 소요시간은 14 28.8초를 보였 고 어려운 기도 시나리오에서는 34.9 41.5초를 보여 본 연구 와 큰 차이는 보이지 않았으나 수련의를 대상으로 한 연구에 서는 정상 기도와 경부고정 시나리오에서 각각 평균 10.7초,
17.6초를 보여 본 연구보다 다소 적은 시간이 소요된 것을 알 수 있다 $[8,10,14]$. 본 연구의 경부고정 시나리오에서 1차 시도 성공률은 $91.3 \%$ 로 매킨토시 후두경의 $73.9 \%$ 에 비해 유의하 게 높았으나 혀부종 시나리오에서는 유의하지 않았다. 학생 이 참여한 마네킹을 대상으로 한 연구에서 오히려 경부강직 시나리오에서 모든 참여자가 성공하여 유의성이 없었고 혀부 종 시나리오에서 성공률 $60 \%$ 로 $47.5 \%$ 를 보여준 매킨토시 후 두경보다 유의하게 높았다[8]. 이 연구의 경부강직 시나리오 는 연출방법이 우리 연구와 달랐으며 혀부종 시나리오에서는 혀부종의 정도를 최대로 설정한 것이 아닌가 생각된다. 다른 연구에서 치아 손상과 식도삽관이 McGrath 비디오 후두경에 서 유의하게 적었으나 본 연구에서는 치아 손상만이 유의하 게 낮았다[14]. 이는 기존의 연구에 비해 다소 적은 시도 횟수 때문으로 생각한다.

설문 결과에서 실습 전후 비디오 후두경의 개념이나 적응 증, 의학교육과정의 적절성에 유의한 인식변화가 있었고, 실 제 임상에서 비디오 후두경의 적용 가능성과 응급기도관리가 필요한 임상 상황에서 대처 능력이 향상되었다는 긍정적인 답변을 하였다. 또한, 응급기도관리가 필요한 상황에서 학생 들은 실습교육 후 비디오 후두경을 선택하여 삽관을 하겠다 는 응답이 실습교육 후 유의하게 증가하였다. Burdett et al. [15]은 어려운 기도 시나리오에서 참여자들이 재삽관 시 후두 경 선호도를 조사하였고 비디오 후두경의 비율이 직접 후두 경에 비해 상당히 높았음을 보고하였다. 우리 연구 역시 실습 전후 동일하게 어려운 기도 시나리오에서 비디오 후두경을 절대적으로 선호하였다. 비디오 후두경에 대한 교육기회는 적거나 '보통이다로 응답한 반면 실제 임상에서 기관내 삽관 이 필요한 상황을 마주칠 가능성은 매우 높다고 인식하고 있 어 재교육이 실시된다면 참여하겠다는 의견이 많았다. 즉, 비 디오 후두경을 통한 기관내 삽관이 임상에서 매우 필요한 술 기임을 학생들은 인식하고 있으나 그에 비해 교육기회는 상 대적으로 부족하다고 생각하였다. Im et al. [16]과 Kovacs et al. [17]은 기관내 삽관술 교육에서 직접적 피드백은 수행 능력 향상에 도움이 된다고 보고하였다. 본 연구에 참여한 학 생들도 시도 간 현장 피드백이 차후 시도에 도움이 되었다고 응답하였고 실패 후 반복시도 역시 숙련도에 긍정적인 영향 을 끼치는 것으로 응답하였다. 다른 연구에서 시도 횟수가 3 
회까지 증가할수록 성공률과 소요시간이 향상되었고 이후 시 도에서 지속적인 매킨토시 후두경에 준하는 성공률을 보여주 었다[13,14].

기관내 삽관 술기를 성공하기 위해서는 여러 세부항목을 수행하여야 한다. 본교에서 학생을 대상으로 한 기관내 삽관 의 평가 체크리스트는 총 16개 항목으로 이루어져 있으며 이 중 “2015 기본 임상술기 지침”에 포함되지 않는 한 항목을 제 외한 15항목에 대해 2013년부터 3년간 자료를 분석하였다. 15 개의 항목 중 6 개의 항목의 수행률이 $50 \%$ 미만이었으며 본 연구와 관련된 항목은 '최종 삽관 성공 여부', '후두경을 전상 방으로 진행(치아손상 여부)', '튜브를 적절한 깊이(21 23 $\mathrm{cm}$ )로 삽관 항목이 있었다. 이 중 $28.0 \%$ 의 학생만이 적절한 깊이로 삽관하였고, $55.9 \%$ 에서 치아손상이 발생하였으며, $39.2 \%$ 만이 삽관에 최종 성공하였다. 본 연구의 시기와 비슷 한 시점의 자료를 분석하기 위해 각 년도의 전반기 평가 결과 만을 가지고 분석하였으나 전반적으로 본 연구보다 성공률은 낮고 합병증은 다소 높은 것으로 조사되었다. 이는 본 연구 전 에 강의와 실습이 이루어졌고 평가 간 현장 피드백과 반복 시 도가 결과에 다소 긍정적인 영향을 끼친 것으로 생각된다.

비디오 후두경을 통한 기관내 삽관은 세부 술기의 교육에 있어 피교육자가 삽관 과정을 직접 보면서 교육을 받을 수 있 다는 장점이 있었다. 직접 후두경은 구강 및 성문까지의 삽관 에 필요한 세부 술기 과정을 학생들은 직접 볼 수 없어 말로 설명 후 피교육생이 직접 확인해야 하는 반면, 비디오 후두경 은 교육 과정 중 후두경의 화면을 통해 세부 술기 능력을 실시 간으로 습득할 수 있어 '성문 및 주변부의 해부학적 구조', '성 문을 노출하는 방법, '기관내 튜브를 조작하여 성문에 삽관하 는 방법 등을 상대적으로 쉽게 교육할 수 있었다. 그러나 이 에 관련된 연구는 아직 없었고, 이번 연구에서도 연구가 이루 어지지 못하여 추가적인 연구가 필요할 것으로 생각된다.

본 연구에는 몇 가지 제한점이 있다. 첫째, 객관적인 교육적 효과 검증에 부족함이 있다. 실습 전후 설문에서 교육적 효과 에 대해 긍정적인 응답을 하였으나 실습 평가에서 시도 간 삽 관시간 단축이라는 내용만으로 교육적 효과의 통계적으로 유 의한 검증이라 말하기 어렵다. 비디오 후두경으로 교육한 군 과 그렇지 않은 군 간의 비교 분석하는 후속 연구가 필요할 것이다. 둘째, 피드백이나 반복 시도에 대한 효과에 대해서도
객관적인 평가가 부족하였다. Im et al. [16]과 같이 피드백을 실시한 군과 그렇지 않는 군의 비교 분석이 필요했고 반복 시 도 또한 다른 문헌과 비슷한 6 8회 정도로 성공률이나 소요 시간이 일정하게 유지되는 횟수까지 시행하지 못했다[13,14]. 셋째, 마네킹을 이용한 시뮬레이션 연구로서 실제 임상 상황 과 차이가 있을 수 있다. 마네킹을 이용한 연구는 실제 응급기 도 관리가 필요한 급박한 임상 상황을 연출하기 어렵고 삽관 실패 시 가져올 재앙적인 결과에 대한 부담이 적어 낮은 성공 률과 시행시간이 오래 걸릴 수 있으며 치아손상이나 식도삽 관의 비율이 높을 수 있다. 또한, 비디오 후두경의 렌즈에 혈 액이 묻거나 뿌영게 흐려질 수 있는 상황도 반영할 수 없었다. 넷째, 직접 후두경은 마취과나 내과에서 실습을 경험한 학생 들이 있었으나 비디오 후두경은 연구 전 조별 약 30분 실습한 것이 전부로 두 후두경을 직접적으로 비교하기에는 무리가 있을 수 있다.

본 연구는 어려운 기도를 연출한 시나리오에서 비디오 후 두경은 적은 합병증으로 보다 높은 성공률로 삽관을 시행할 수 있고 시도가 반복될수록 술기 소요시간은 줄었다. 실습 전 후 설문에서 비디오 후두경의 교육을 통해 기관내 삽관 및 임 상 대처능력에 대한 자신감 상승을 보였고 적은 교육기회에 비해 높은 재교육 의지를 보여 충분한 동기부여가 됨을 확인 하였다. 또한 삽관 시 높은 비디오 후두경의 선호도를 보여 실 습 평가에서 보인 결과를 설문에서도 확인할 수 있었다. 의학 교육 과정에 비디오 후두경을 통한 기관내 삽관 술기가 포함 된다면 향후 기관내 삽관 교육이 더 효과적으로 이루어질 것 으로 생각한다.

\section{Acknowledgements: None.}

Funding: None.

Conflicts of interest: None.

\section{REFERENCES}

1. Nouruzi-Sedeh P, Schumann M, Groeben H. Laryngoscopy via Macintosh blade versus GlideScope: success 
rate and time for endotracheal intubation in untrained medical personnel. Anesthesiology 2009; 110: 32-37.

2. Griesdale DE, Liu D, McKinney J, Choi PT. Glidescope (R) video-laryngoscopy versus direct laryngoscopy for endotracheal intubation: a systematic review and metaanalysis. Can J Anaesth 2012; 59: 41-52.

3. Orebaugh SL. Difficult airway management in the emergency department. J Emerg Med 2002; 22: 31-48.

4. Marx JA, Hockberger RS, Walls RM, Biros MH. Rosen's emergency medicine: concepts and clinical practice. 8th ed. Philadelphia, USA: Elsevier Saunders; 2014. p 9.

5. Kita S, Higashi K, Matsuo M, Sano H, Aoyama K, Takenaka I. Head extension during laryngoscopy for obtaining a best glottic view: comparison of the McGrath and Macintosh laryngoscopes. Masui 2014; 63: 13001305.

6. De Jong A, Molinari N, Conseil M, Coisel Y, Pouzeratte Y, Belafia F, Jung B, Chanques G, Jaber S. Video laryngoscopy versus direct laryngoscopy for orotracheal intubation in the intensive care unit: a systematic review and meta-analysis. Intensive Care Med 2014; 40: 629639.

7. Sakles JC, Mosier J, Chiu S, Cosentino M, Kalin L. A comparison of the C-MAC video laryngoscope to the Macintosh direct laryngoscope for intubation in the emergency department. Ann Emerg Med 2012; 60: 739-748.

8. Si JW, Lee SB, Do BS. Comparison of the Macintosh laryngoscope and the GlideScope $(\mathrm{R})$ video laryngoscope in easy and simulated difficult airway scenarios: a manikin study. J Korean Soc Emerg Med 2009; 20: 604-608.

9. Sim GS. Comparison of video laryngoscope and direct laryngoscope on rapidity and accuracy in tracheal intubation by paramedic. J Korean Soc Emerg Med
Technol 2010; 14: 5-18.

10. Son SH, Park SO, Baek KJ, Choi PJ. Comparison of the Macintosh laryngoscope and the Disposcope endoscope (R) in both normal airway and manual in-line stabilization for suspected cervical spine injury patients: a simulation study using an airway training manikin. J Korean Soc Emerg Med 2011; 22: 628-634.

11. Walls RM, Murphy MF. Manual of emergency airway management. 4th ed. Kang KH, et al., translator. Seoul, Korea: Koonja; 2013. p 130, 134, 267.

12. Langvad S, Hyldmo PK, Nakstad AR, Vist GE, Sandberg M. Emergency cricothyrotomy: a systematic review. Scand J Trauma Resusc Emerg Med 2013; 21: 43.

13. Piepho T, Weinert K, Heid FM, Werner C, Noppens RR. Comparison of the McGrath(R) Series 5 and GlideScope (R) Ranger with the Macintosh laryngoscope by paramedics. Scand J Trauma Resusc Emerg Med 2011; 19: 4.

14. Ray DC, Billington C, Kearns PK, Kirkbride R, Mackintosh K, Reeve CS, Robinson N, Stewart CJ, Trudeau T. A comparison of McGrath and Macintosh laryngoscopes in novice users: a manikin study. Anaesthesia 2009; 64: 1207-1210.

15. Burdett E, Ross-Anderson DJ, Makepeace J, Bassett PA, Clarke SG, Mitchell V. Randomized controlled trial of the A.P. Advance, McGrath, and Macintosh laryngoscopes in normal and difficult intubation scenarios: a manikin study. Br J Anaesth 2011; 107: 983-988.

16. Im SJ, Yune SJ, Kang SY, Lee SY, Kim HK, Jeong HJ. The effect of eirect feedback in teaching endotracheal intubation. Korean J Med Educ 2007; 19: 325-333.

17. Kovacs G, Bullock G, Ackroyd-Stolarz S, Cain E, Petrie D. A randomized controlled trial on the effect of educational interventions in promoting airway management skill maintenance. Ann Emerg Med 2000; 36: 301-309. 